\title{
Entre o Patrimonialismo e a Democracia: Como se dá a Sucessão Governamental em um Município do Interior de Minas Gerais
}

\author{
Carla de Faria1 \\ Giovana Daniela de Lima ${ }^{2}$ \\ Alexander Gonçalves Pereira ${ }^{3}$ \\ Dany Flávio Tonelli4 \\ Universidade Federal de Lavras
}

\section{RESUMO}

O objetivo desta pesquisa exploratória é apresentar os conceitos centrais de democracia em Rousseau e demonstrar como a dominação patrimonialista tem usurpado o caráter democrático das eleições municipais, por meio de uma análise da campanha eleitoral de 2016 no município de Nepomuceno-MG. Os procedimentos técnicos utilizados foram pesquisa bibliográfica, pesquisa documental e estudo de caso, com abordagem qualitativa. Por meio da pesquisa bibliográfica foram apresentados os conceitos de democracia de Rousseau e como este conceito é visto na atualidade. Discutiu-se que a dominação patrimonialista tem sido uma ferramenta para manipular os eleitores desde o início da história do processo eleitoral brasileiro e, por meio de estudo de caso e pesquisa documental foi possível identificar características do patrimonialismo no recente processo eleitoral do município em análise. O resgate da história eleitoral brasileira associado a este estudo conduz à reflexão sobre o fato de que a herança patrimonialista compromete o caráter democrático das eleições municipais no país, corroborando para a perpetuação das relações de dependência entre dominantes e dominados, o que reafirma o estágio incipiente da democracia no Brasil, principalmente quando voltamos ao conceito de Rousseau que via nas eleições o ápice de seu exercício. Conclui-se que o acordo tácito de poder, baseado no fator econômico, se mantém entremeado na democracia brasileira e apenas por meio do voto não é possível romper com essa estrutura patrimonialista e personalista.

Palavras-chave: democracia; dominação patrimonialista; eleições.

\section{ABSTRACT}

The objective of this exploratory research is to present the central concepts about Rousseau's democracy and to demonstrate how the patrimonial domination has usurped the democratic character of the municipal elections, through an analysis of the 2016 electoral campaign in the municipality of Nepomuceno-MG. The technical procedures used were bibliographic research, documentary research and case study, with a qualitative approach. Through the bibliographical research were presented the concepts about Rousseau's democracy and how this concept is seen today. It was argued that patrimonial domination has been a tool to manipulate voters since the beginning of the history of the Brazilian electoral process and, through case study and documentary research, it was possible to identify characteristics of patrimonialism in the recent electoral process of the municipality in analysis. The rescuing of the Brazilian electoral history associated to this study leads to the reflection on the fact that the patrimonial inheritance compromises the democratic character of the municipal elections in the country, corroborating for the perpetuation of the dependency relations between the dominant and the dominated, which reaffirms the incipient stage of the Democracy in Brazil, especially when we return to the concept of Rousseau who saw in the elections the apex of his exercise. It is concluded that the tacit agreement of power, based on the economic factor, remains intertwined in the Brazilian democracy and only through the vote can't break with this patrimonialist and personalist structure.

Keywords: Democracy, Patrimonial Rule, Elections

\footnotetext{
${ }^{1}$ Mestranda em Administração Pública da UFLA. Docente curso de Ciências Contábeis do Centro Universitário de Formiga - MG - carla.faria218@gmail.com

2 Mestranda em Administração Pública da Universidade Federal de Lavras UFLA - giovanadanieladelima@gmail.com

${ }^{3}$ Mestrando em Administração Pública da Universidade Federal de Lavras UFLA - alexsanderadvocacia@yahoo.com.br

${ }^{4}$ Doutorado em Administração pela UFLA. Docente curso de Administração Pública da Universidade Federal de Lavras UFLA - danytonelli@dae.ufla.br
} 


\section{RESUMEN}

El objetivo de esta investigación exploratoria es presentar los conceptos centrales de democracia en Rousseau y demostrar cómo la dominación patrimonialista ha usurpado el carácter democrático de las elecciones municipales, a través de un análisis de la campaña electoral de 2016 en el municipio de Nepomuceno-MG. Los procedimientos técnicos utilizados fueron investigación bibliográfica, investigación documental y estudio de caso, con abordaje cualitativo. Por medio de la investigación bibliográfica se presentaron los conceptos de democracia de Rousseau y cómo este concepto es visto en la actualidad. Se discutió que la dominación patrimonialista ha sido una herramienta para manipular a los electores desde el inicio de la historia del proceso electoral brasileño y por medio de estudio de caso e investigación documental fue posible identificar características del patrimonialismo en el reciente proceso electoral del municipio en análisis. El rescate de la historia electoral brasileña asociado a este estudio conduce a la reflexión sobre el hecho de que la herencia patrimonialista compromete el carácter democrático de las elecciones municipales en el país, corroborando para la perpetuación de las relaciones de dependencia entre dominantes y dominados, lo que reafirma el estadio incipiente de la democracia en Brasil, principalmente cuando volvemos al concepto de Rousseau que veía en las elecciones el ápice de su ejercicio. Se concluye que el acuerdo tácito de poder, basado en el factor económico, se mantiene entremezclado en la democracia brasileña y sólo por medio del voto no es posible romper con esa estructura patrimonialista y personalista.

Palabras clave: democracia; dominación patrimonialista; elecciones.

\section{Introdução}

Em sua obra Leviatã, Thomas Hobbes (2005) reconhece apenas três formas de governo, baseadas na diferença do soberano. Se o poder soberano pertence a um só homem, temos a monarquia, se pertence a todos, a forma de poder é a democracia, e se estiver concentrado nas mãos de uma classe, chama-se aristocracia. Em todas elas, a decisão de sucessão encontra-se nas mãos do próprio soberano, caso contrário o Estado encontra-se dissolvido e o direito passa a ser de quem o apoderar. Como na democracia o poder soberano é exercido por todos e é impossível que "todos" venham a faltar, não há o que se falar em direito de sucessão. Nesse caso, o que há é a sucessão daquele que exerce a função de governar.

Para Rousseau (1989), o soberano é sempre um ser coletivo, formado por todos. Sendo a soberania o exercício da vontade geral, é inalienável e indivisível, apenas o poder é transferível. Assim, o poder do soberano não pertence, mas é "confiado" a um, no caso da monarquia ou a vários, no caso da aristocracia. Para ele, não é possível que a democracia exista em seu conceito original, tendo em vista que é impossível que o povo esteja sempre reunido para cuidar dos interesses públicos. Dessa forma, o único momento em que o poder soberano é realmente exercido pelo povo em uma democracia é nas eleições, ou seja, o único momento em que o povo é realmente "livre".

No entanto, mesmo este ato pode perder seu caráter de liberdade ou sua essência democrática desde que as pessoas não exerçam sua vontade, mas a vontade de outro. No passado, a expropriação da vontade popular era notória no Brasil. Os coronéis utilizavam seu poder patrimonialista para impor o voto de cabresto, que se baseava no controle do poder político pelo abuso de autoridade e na compra de votos. Atualmente, mesmo com a evolução do processo eleitoral, da administração pública e da própria sociedade brasileira essas práticas não foram esquecidas, apenas camufladas. O processo eleitoral de 2016 no município de Nepomuceno-MG foi palco de diversas movimentações políticas no sentido de polemizar o processo e manipular a intenção de voto dos eleitores.

Levando-se em consideração que a cultura predominante em relação à forma de escolha dos governantes é similar à maioria dos eleitores brasileiros, é possível generalizar que a realidade encontrada no município em estudo repete-se por todo o território nacional. Neste sentido, o objetivo desse artigo é apresentar os conceitos centrais acerca da democracia de Rousseau e demonstrar como a dominação patrimonialista tem usurpado o caráter democrático das eleições presidenciais, por meio de uma análise da campanha referente ao último processo eleitoral. Assim, permeia-se a seguinte questão norteadora: como as práticas de dominação patrimonialista estão sendo utilizadas pelos atores políticos no processo eleitoral brasileiro, de forma a manipular o poder soberano dos cidadãos?

Para realização deste trabalho, foi desenvolvida uma pesquisa de natureza exploratória, pois se espera conhecer com maior profundidade o assunto, torná-lo claro e facilitar o seu entendimento. De acordo com Gil (2008), este tipo de investigação envolve levantamento bibliográfico, entrevista com pessoas que tiveram experiência prática com o problema pesquisado e análise de problemas que estimulem a compreensão. 
A pesquisa exploratória pode ser bibliográfica ou se desenvolver por meio de estudo de caso. A pesquisa bibliográfica consiste no levantamento de referências teóricas já analisadas e publicadas, seja em meio físico ou eletronicamente. Já o estudo de caso baseia-se na observação de uma entidade bem definida, com o objetivo de se conhecer o assunto em profundidade (Gil, 2007).

Dessa forma, o presente estudo englobou, além da pesquisa bibliográfica, um estudo de caso, por meio do qual, foram analisados os fatos que envolveram a campanha eleitoral de 2016 para a prefeitura de Nepomuceno, Minas Gerais.

Os fatos narrados são provenientes da pesquisa documental de processos e sentenças judiciais no âmbito da Justiça Eleitoral e da observação de um dos autores do presente artigo, que os vivenciou enquanto servidor público municipal.

Portanto, a abordagem da pesquisa constituiu-se de forma qualitativa, sendo que se caracterizou pela vinculação entre a realidade objetiva e a subjetividade do sujeito, o que torna impossível a tradução das observações em números. Ou seja, não foram utilizados métodos estatísticos para apuração dos resultados, mas são resultado da interpretação dos fatos apurados pelos pesquisadores, que se tornaram, dessa forma, o instrumento chave da pesquisa (Kauark; Manhães; Medeiros, 2010).

Este artigo torna-se relevante na medida em que discute o cenário das campanhas eleitorais diante do conceito de dominação patrimonialista, buscando-se atentar sobre a fragilidade do aspecto democrático no processo eleitoral brasileiro, e abre lacunas para novas pesquisas no sentido de se preservar a democracia por meio do desenvolvimento de mecanismos que visem reduzir a influência perniciosa das técnicas de dominação patrimoniais.

Este ensaio teórico foi estruturado em seis partes, além da introdução. A primeira apresenta os aspectos conceituais de soberania e democracia partindo da teoria dos filósofos contratualistas; a segunda discute o conceito e democracia no contexto atual em consonância com a realidade brasileira; a terceira discorre sobre o patrimonialismo e suas formas de manifestação; a quarta remonta à história do processo eleitoral atrelado à influência do poder de mando dos coronéis brasileiros e a quinta trata do contexto atual, apresentando um breve relato sobre o desenrolar das eleições de 2016 no município de Nepomuceno-MG. Por fim, retoma-se o objetivo do trabalho e são apresentadas as considerações finais.

\section{Soberania e Democracia à Luz da Filosofia Contratualista}

Para a compreensão dos conceitos de soberania e democracia, é interessante retroceder às ideias de concepção do Estado formuladas pelos filósofos contratualistas dos séculos XVII e XVIII. O ponto principal dessa teoria é que houve uma situação anterior ao Estado politicamente instituído, onde as pessoas viviam de forma individual, constituindo o estado de natureza. A necessidade de proteção aos direitos naturais do homem, como a vida e a propriedade, resultou na alienação dos seus direitos individuais para a construção de um Estado civil político (Souza, 2010).

O primeiro filósofo dessa teoria foi Thomas Hobbes, em sua obra Leviatã, escrita em 1651. Nessa obra, ele afirma que os homens viviam em estado permanente de guerra, de todos contra todos. Para conseguirem a defesa e a paz necessárias, cedem seus direitos individuais para formação de um Estado, representado pela metáfora do Leviatã, um Deus mortal que está abaixo apenas do Deus imortal, ao qual todos os indivíduos devem temer e respeitar, mas ao qual todos pertencem. Dentro deste conceito, o poder soberano concentra-se na figura do governante, ao qual tudo é sua propriedade, inclusive a vida dos cidadãos, e só a ele cabe decidir o que é bom ou mal. Conforme a base do conceito patrimonialista, não há distinção entre o público e o privado. Os súditos só têm direito à concessão da propriedade pelo Estado (Hobbes, 2005).

Conforme já mencionado, para Hobbes (2005), existem apenas três formas de governo: monarquia, onde o poder soberano encontra-se nas mãos de um só homem; aristocracia, concentrado nas mãos de uma classe e democracia, que consiste no próprio poder popular, destinado a uma assembleia de todos. A decisão 
da sucessão encontra-se nas mãos do soberano, portanto, o maior problema consiste na escolha do sucessor na monarquia, pois na aristocracia, a substituição de um dos membros é feita mediante eleição pelos restantes. No caso da democracia, não existe sucessão, pois é impossível que todos faltem a um só tempo.

Segundo Locke (1998), o estado de natureza é um estado de extrema liberdade, sem subordinação ou sujeição. A união das pessoas em torno de um Estado político é para se evitar o estado de guerra e com isso, garantir a proteção da propriedade privada, que engloba os conceitos de vida, bens e liberdade. "O fim maior e principal para os homens unirem-se em sociedades políticas e submeterem-se a um governo é, portanto, a conservação de sua propriedade" (Locke, 1998, p. 495). Sua visão é bastante individualista e foi precursora do liberalismo, que veio à tona na época da Revolução Americana e da Revolução Francesa, ocorridas no final do século XVIII. Suas ideias também estão presentes na constituição de diversos Estados liberais (Souza, 2010).

Nesse modelo, é necessária a divisão do Estado em três poderes: o legislativo, o judiciário e o executivo. O legislativo é o poder supremo e aquele que o detém deve governar segundo as leis promulgadas e consentidas pelo povo. O autor também reconhece três formas de governo, a democracia, a oligarquia (quando um pequeno grupo de homens tem o poder de elaborar as leis) e a monarquia (Locke, 1998).

Os autores supracitados se preocupam mais com a separação dos poderes do que com a forma de governo, dando pouca relevância a este último aspecto. Rousseau, porém, amplia as discussões sobre o assunto enfatizando as características da democracia (Souza, 2010).

Rousseau (1989) possui uma visão mais negativista do pacto social, tendo em vista que, para ele, os homens perdem seu direito à liberdade absoluta. Os homens nascem livres e não é natural que obedeçam a outro. Portanto, é importante encontrar

\footnotetext{
uma forma de associação que defenda e proteja de toda a força comum a pessoa e os bens de cada associado, e pela qual, cada um, unindo-se a todos, não obedeça, portanto, senão a si mesmo, e permaneça tão livre como anteriormente (Rousseau, 1989, p. 24).
}

E a única forma possível para que o homem continue obedecendo apenas a si mesmo é por meio da participação na elaboração das leis que irão determinar como será seu comportamento. Partindo-se deste pressuposto, a soberania consiste no exercício da vontade popular e, por assim ser, inalienável, porque a vontade não pode ser delegada a outro, e indivisível, porque é a representação da vontade geral e não individual ou de uma classe de pessoas. Dessa forma, o que pode ser transmitido é apenas o poder e nunca a soberania.

Sob esse prisma, o poder político pode então ser dividido em: legislativo, que consiste na soberania popular, na transformação da vontade geral em leis que irão governar os cidadãos; e executivo que representa o poder soberano que faz com que as leis elaboradas e aprovadas por todos sejam cumpridas (Rousseau, 1989).

Para o exercício do poder, Rousseau (1989) também reconhece as três formas de governo: a monarquia, onde o governo é representado por um; a aristocracia, quando o poder é confiado a uma classe e a democracia: poder exercido pelo povo em conjunto com o poder legislativo. Como a vontade popular consiste na própria soberania, o autor não reconhece a democracia representativa, inclusive, afirma que ela nunca existiu de forma plena, porque, para que fosse exercida em sua totalidade, seria necessário que, além de ocorrer de forma direta, todos deveriam estar em igualdade de condições. Um povo, representado por deputados no exercício do poder legislativo, perde sua liberdade porque transfere a responsabilidade pela elaboração das leis que deverá acatar, ou seja, deixa de obedecer à sua vontade para se curvar à vontade de outro. Assim, a democracia só ocorre de forma pura quando os cidadãos realmente participam do processo decisório e isso só acontece no momento das eleições.

\section{A Democracia sob um Olhar Mais Recente}


Para Bresser-Pereira (2009), a democracia só pode ser considerada efetivamente implantada a partir do sufrágio universal, que representou a conquista ampla dos direitos políticos. Nos países desenvolvidos isso só ocorreu no século XIX, após a revolução capitalista. Porém, o marco da sua implantação, ou seja, o fato do direito ao voto ter sido estendido a todos os cidadãos, não significou que passou a ser realmente exercida. Na primeira metade do século XX, na democracia exclusivamente representativa, os políticos eleitos só se interessavam pela opinião dos eleitores até as eleições. A partir daí, tomavam suas próprias decisões. Os eleitores, por sua vez, só estavam preocupados com seus próprios interesses, sem se envolver com ações voltadas para o interesse público. No século XXI, começam a surgir esforços na busca pela substituição deste tipo de democracia, denominada elitista, pela democracia deliberativa ou republicana. Embora o modelo atual ainda esteja distante do conceito de democracia deliberativa em sua amplitude, já apresenta uma evolução significativa em relação ao modelo clássico.

Para a defesa dos seus direitos republicanos que "são o direito que todos os cidadãos têm ao uso público da res publica - do patrimônio público (ambiental, cultural e econômico)-inclusive o fluxo de recursos envolvido nas receitas do Estado e das organizações públicas não-estatais" (Bresser-Pereira, 2009, P.127), os cidadãos tornam-se mais críticos e mais conscientes da necessidade de sua participação para o desenvolvimento da nação e a consecução dos objetivos da sociedade civil. Nesse modelo, as decisões são tomadas mediante a participação efetiva das organizações sociais que se reúnem e discutem ampla e exaustivamente os assuntos em questão. Caso não haja um consenso, as alternativas são escolhidas por meio do voto, sendo acatada a decisão da maioria. Dessa forma, as ações dos governantes são mais controladas pelos eleitores e ambos, governados e governantes, tornam-se mais responsáveis pelas políticas adotadas. É claro que, sempre haverá políticos mais interessados em se manter no poder para enriquecer que para o desenvolvimento da nação, assim como, sempre haverá cidadãos mais voltados aos interesses próprios que ao bem comum, mas também haverá aqueles para os quais o mais importante é o interesse público. E, embora, nenhuma nação esteja plenamente madura para a existência desse tipo de democracia em sua completude,

as organizações da sociedade civil estão presentes em toda parte, lutando para fazer valer suas opiniões, informando, argumentando, debatendo [...] e podem sofrer todo tipo de limitação, mas elas acabam conferindo à democracia um caráter republicano (Bresser-Pereira, 2009, p.202).

Em relação ao Brasil, a história política brasileira dificulta muito o exercício efetivo da democracia. No período da colonização e da dominação da coroa portuguesa, prevaleciam apenas os interesses do rei e os aspectos patrimonialistas que marcaram aquele período se arraigaram à cultura brasileira e estão presentes até hoje. Muito embora, existam ações para efetivamente implantar a democracia no país, como, por exemplo, o próprio texto constitucional, o que se vê na prática é um distanciamento entre políticos e demais cidadãos, como se constituíssem classes diferentes, com interesses diferentes. Além do pouco envolvimento dos cidadãos, devido à própria cultura patrimonialista de corrupção e clientelismo, existe a possibilidade que as organizações e instituições sociais se tornem influentes e passem a agir em interesse próprio. Mesmo assim, este tipo de participação social é um importante passo rumo à democracia. A esperança é a criação de valores cívicos que levem à participação efetiva da sociedade no processo político para que realmente prevaleça o interesse público (Andrade, de Carvalho Castro \& Pereira, 2012).

E, neste sentido, as últimas décadas promoveram a evolução do pensamento dos cidadãos a respeito da democracia, no que diz respeito aos princípios do regime, como a liberdade, e a importância dos procedimentos e das instituições que o envolve. Mesmo que a caminhada rumo ao exercício da democracia seja lenta, os brasileiros já começam a demonstrar maior preocupação com a corrupção e com as instituições de controle e a responsabilização dos políticos (Moisés, 2010). O próximo passo é a conscientização do quanto as eleições representam para o processo democrático e se desprendam das amarras patrimonialistas no momento da escolha de seus representantes. 


\section{As Manifestações da Forma de Dominação Patrimonialista}

De uma forma visionária, os filósofos contratualistas preconizaram a própria alternância de poder entre Estado, Mercado e Sociedade Civil: Hobbes destaca o poder do Estado na figura do Leviatã; Locke ressalta o poder do mercado e do liberalismo quando enaltece a importância da propriedade e Rousseau concentra o poder na sociedade quando afirma que a soberania representa a vontade popular e que a legitimidade das leis só é alcançada por meio da sua elaboração e aprovação pelo povo.

Essa alternância de poderes consiste na base dos paradigmas de administração pública: o patrimonialismo, que vigorou até o final do século XIX, marcou o período monárquico absolutista, onde o patrimônio público e o privado confundiam-se; o burocrático, que surgiu no início do século XX em contraposição aos vícios do paradigma anterior, tendo em vista a necessidade da distinção entre Estado e mercado para atendimento às necessidades do capitalismo industrial emergente; o modelo gerencial, que começou a ser discutido em final dos anos 1980, pautado na busca pela eficiência, eficácia e efetividade das ações governamentais e no compromisso com a obtenção de resultados e desempenho da gestão; e, a gestão social, discutida a partir da década de 1990, com foco na participação popular nas decisões políticas. Embora tenham surgido em momentos diferentes da história e por razões distintas, um modelo não foi completamente extinto, pelo contrário, continuam coexistindo e influenciando os caminhos das nações, sobretudo, os do Brasil (Bresser-Pereira, 2008; Costa, 2008; Abrucio, 2007).

Assim pode-se dizer que, embora a sociedade comece a reconhecer sua soberania, a administração pública, o governo e os governantes ainda possuem estreita relação com o conceito de dominação herdados do patrimonialismo e suas formas de manifestação. Para Weber (1999), a ideia de dominação está associada ao poder de imposição de vontade a terceiros, especificando que tal poder decorre pelo interesse ou pela autoridade. Weber (1999) ressalta, no entanto, que, do ponto de vista sociológico, interessa o "poder de mando autoritário", a dominação associada à administração, por meio da qual a vontade do dominador influencia de tal modo as ações do dominado que estes a realizam como se fosse sua própria vontade.

A legitimidade da dominação pode fundamentar-se "em relações tradicionais de autoridade", no caso da dominação tradicional; "em regras racionais", caracterizando a dominação legal; ou "no carisma pessoal", configurando a dominação carismática. (de Oliveira, da Silva e Oliveira \& dos Santos, 2011 apud Weber 1999).

A dominação do tipo tradicional baseia-se na "autoridade pessoal", na "tradição sagrada", sendo "tipicamente representada pelo patriarcalismo." (Weber, 1999). A relação entre o senhor e seus dominados fundamenta-se no direito legítimo ao poder, conforme destaca Max Weber (1999):

[...] em regra, porém, o senhor patrimonial político está unido com os dominados numa comunidade consensual, a qual existe também independentemente de um poder militar patrimonial autônomo e se baseia na convicção de que o poder senhorial tradicionalmente exercido seja o direito legítimo do senhor (Weber, 1999, 246).

Esta estrutura de dominação constituiu a base do Estado absolutista, no qual o soberano é o senhor absoluto e os governados seus súditos, nos moldes do pacto social hobbesiano. (Cançado, Pereira \& Tenório, 2013). Nos Estados absolutos, o poder político e econômico concentrava-se na figura do soberano. O patrimônio público se confundia com o particular do soberano. A concessão de títulos e terras em troca da fidelidade dos súditos garantia a manutenção do poder dominante e abria espaço para práticas como o clientelismo, a corrupção e o nepotismo. (Bresser-Pereira, 2009: Cançado, Pereira \& Tenório, 2013).

Este arranjo administrativo configura o paradigma patrimonialista, no qual a administração política e todo o aparato estatal são entendidos como uma extensão do poder do soberano. Cançado, Pereira e Tenório (2013) enumeram as características gerais do modelo de administração patrimonial, a saber:

[...] caráter personalista do poder; ausência de uma esfera pública contraposta à privada; a lógica subjetiva e causuística do sistema jurídico; irracionalidade fiscal; tendência à corrupção do quadro administrativo; relações de lealdade pessoal; ausência de limites entre os bens e recursos públicos e privados; clientelismo, corrupção e nepotismo; a função do Estado e do serviço público é dar emprego e favorecer aliados. (Cançado, Pereira \& Tenório, 2013, p. 90) 
Por meio da análise do paradigma patrimonial, é possível compreender determinados comportamentos da sociedade brasileira que comprometem a adoção de uma democracia mais pura, assim como, outros problemas que afligem o país.

No Brasil, o patrimonialismo decorre da colonização portuguesa, que reproduziu em terras brasileiras, tanto no período colonial quanto no imperial, as características do Estado patrimonial e estamental português. A proclamação da República não alterou a estrutura patrimonialista do Estado, promovendo apenas alterações no poder de mando, agora encarnado na figura dos "coronéis" (Faoro, 2001: Costa, 2008).

\section{A História do Processo Eleitoral Brasileiro}

O direito ao voto no Brasil antecede à independência do país. Durante o período colonial, realizavamse, eleições para cargos administrativos nas vilas e nas cidades. Eram eleições indiretas, nas quais os "homens bons - aqueles maiores de 25 anos, católicos, casados ou emancipados, proprietários de terra e sem impureza de sangue - e o povo escolhiam os eleitores. Os eleitores, por sua vez, deveriam eleger os ocupantes dos cargos administrativos. Embora o povo - os demais homens livres - pudessem escolher os eleitores, apenas os homens bons poderiam ser eleitos. (Leal, 2012: Nicolau, 2012)

Após a independência, os deputados e senadores passaram a ser eleitos por meio de eleições indiretas. Os indivíduos maiores de 25 anos ou maiores de 21 anos, caso fossem casados, e com renda mínima anual de cem mil réis eram considerados votantes e poderiam participar nas eleições de primeiro grau, nas quais eram escolhidos os eleitores que, efetivamente, elegiam os parlamentares, nas eleições de segundo grau. Só se qualificavam na categoria de eleitor os indivíduos com renda anual superior a duzentos mil réis. Não havia proibição quanto ao voto de analfabetos, no entanto, exigia-se a assinatura dos votantes nas eleições de primeiro grau. O voto não era secreto e havia a possibilidade de voto por procuração. Posteriormente, em 1842 foi instituído a alistamento prévio e a obrigatoriedade de os votantes comparecerem aos locais de votação, extinguindo-se o voto por procuração. A partir de 1876, os votantes passaram a utilizar uma cédula que deveria ser fechada antes de ser depositado na urna, o que representou o primeiro caráter sigiloso das eleições brasileiras. A Lei Saraiva, de 1882, promoveu duas mudanças no sistema eleitoral brasileiro, quais sejam: o fim do voto indireto e a obrigatoriedade que os eleitores soubessem ler e escrever. (Leal, 2012: Nicolau, 2012)

As características do sistema eleitoral brasileiro durante o Império evidenciam a permeabilidade aos mais diversos tipos de fraudes, com vistas a garantir a sustentação parlamentar aos interesses da Coroa. Nicolau (2012, p. 43) apud Souza (1979) elenca as diversas manobras usadas para vencer as eleições, quais sejam: "adulteração da lista de votantes; controle da mesa eleitoral; uso de ameaças e violências por intermédio de "capangas"; voto de eleitores fantasmas (o "fósforo"); adulteração das atas eleitorais (eleições "a bico de pena")".

Entretanto, o fim do Império não colocou um ponto final às práticas clientelistas existentes na política brasileira. Ao contrário, elas continuaram presentes no novo regime: a sociedade era hierarquicamente composta por protetores e protegidos. Sendo que os protetores ajudavam parentes e amigos por meio do uso dos recursos públicos, o que lhes garantia a fidelidade política dos protegidos (Carvalho, 2000). Dessa forma, a proclamação da República trouxe para o cenário político brasileiro o fenômeno nominado "coronelismo", como forma de assegurar a manutenção do poder dominante, mesmo diante do novo regime político. As lideranças regionais, conhecidas por coronéis, garantiam, por meio do voto de cabresto, a eleição daqueles que os interessavam e em troca recebiam as condições necessárias para a manutenção de sua dominação econômica e social na região. O coronel figurava como o provedor local, que concedia favores à população, pagos com a fidelidade do voto, numa típica relação clientelista entre dominante e dominados. (Carvalho, 1997: Faoro, 2001: Costa, 2008: Leal, 2012). 
A lei eleitoral ampliou o eleitorado, por meio da extinção da restrição referente à renda mínima para que o indivíduo tivesse direito ao voto e pela redução da idade mínima dos eleitores para 21 anos. Também foi instituído o voto secreto, no entanto, o dispositivo denominado "voto a descoberto" possibilitava a coerção por parte dos coronéis. Pelo "voto a descoberto" o eleitor levava ao local de votação duas cédulas, após serem igualmente datadas e rubricadas pelos mesários, uma era depositada na urna e a outra, devolvida ao eleitor, era usada para assegurar que o voto havia sido no candidato do coronel. (Nicolau, 2012).

A manutenção do poder vigente associou o poder de coerção dos coronéis à manutenção de práticas fraudulentas ao longo de todo o processo eleitoral. Nicolau (2012, p. 68) destaca os principais mecanismos de fraude eleitoral no período, quais sejam: "eleição a bico de pena", que consistia no voto aberto e não-secreto, o que possibilitava o controle dos eleitores pelos caciques políticos, e a "degola", prática em que o Legislativo, a quem cabia reconhecer o resultado das eleições, substituía os eleitos que não tinham o apoio dos ricos fazendeiros por "apadrinhados" que não haviam ganham democraticamente a disputa.

A partir do fim da República Velha o sistema eleitoral brasileiro passou por sucessivas mudanças, com vistas a reduzir as fraudes e promover a democratização das instituições políticas do país. Com a ascensão do Estado Novo instituiu-se a obrigatoriedade de alistamento e de voto, além da extensão do direito ao voto às mulheres. No entanto o avanço mais significativo refere-se à mudança no processo apurativo: antes, a contagem de votos realizava-se após a votação, sendo responsabilidade da própria mesa; a partir de então, as urnas passaram a ser lacradas após a eleição e transferidas para as capitais dos estados, para serem apuradas pelos Tribunais Regionais Eleitorais. As mudanças representaram avanços, no entanto, não eliminaram as fraudes e as coerções que ocorriam principalmente no interior do país. A partir de 1955, passou a ser adotada a "folha individual de votação", contendo foto e informações pessoais do eleitor. Instituise, então a obrigatoriedade de se votar em uma única seção. Em 1985 instituiu-se o sufrágio universal. Já a Constituição de 1988 ampliou o direito ao voto para jovens a partir de 16 anos, além de introduzir a possibilidade de abstenção devidamente justificada. Não obstante a evolução, houve a persistência de condutas fraudulentas, associadas à manutenção de práticas clientelistas e ao uso do poder de coação, que continuaram influenciando o resultado das eleições (Nicolau, 2012).

A partir de 1996, o Tribunal Superior Eleitoral passou a substituir a eleição por meio de cédulas de papel pela urna eletrônica, o que, para Nicolau (2012), representou um avanço na busca de se eliminar as fraudes eleitorais no Brasil. No entanto, o sistema de votação eletrônica não elimina as práticas clientelistas ainda tão presentes na política brasileira.

\section{Um Breve Relato das Eleições Municipais de 2016 no Município de Nepomucemo/MG}

A cidade de Nepomuceno em Minas Gerais foi fundada em 30 de agosto de 1911, estando situada na região Campo das Vertentes. A cidade integra a microrregião de Lavras, e possui de acordo com o censo de 2010, 25.733 habitantes, sendo a população estimada para 2016 de 26.977 habitantes (IBGE, 2010).

Nas eleições de 2016, segundo o Tribunal Regional Eleitoral, no município de Nepomuceno havia 20.561 eleitores aptos para participarem do pleito. Foram lançadas três candidaturas ao cargo Prefeito: Luiz Fernando Pereira Souza, pelo Partido Republicano da Ordem Social (PROS); José Silvio de Carvalho, pelo Partido Trabalhista Brasileiro (PTB); e Luiza Maria Lima Menezes, pelo Partido Social Democrático (PSD). Dentre os pré-candidatos, somente o Sr. José Sílvio de Carvalho já havia exercido o cargo de Prefeito Municipal, por dois mandatos: 1\%01/2005 a 31/12/2008; 1\%01/2009 a 08/12/2009. Sílvio Lucas, como é conhecido, não conseguiu completar o segundo mandato, devido sua cassação pelo Tribunal Regional Eleitoral, por captação ilícita de votos na campanha eleitoral de 2008, onde ficou constatada a distribuição de cestas básicas para beneficiar eleitores que não estavam regularmente inscritos em programas da Secretaria Municipal de Assistência Social.

No processamento do registro das candidaturas para as Eleições de 2016, o Ministério Público de Minas Gerais e a coligação da candidata Luiza Maria Lima Menezes apresentaram impugnação à candidatura do Sr. José Silvio de Carvalho (PDT), sob os seguintes argumentos aduzidos na sentença de primeira instância da Justiça Eleitoral: primeiro, o impugnado teve seu mandato cassado por compra de 
votos nas Eleições de 2008, ficando inelegível pelo prazo de 8 anos; segundo, que as contas do candidato, quando ocupou o cargo de Prefeito no município de Nepomuceno no exercício de 2008, foram rejeitadas pelo Tribunal de Contas Estadual, e posteriormente pela Câmara Municipal de Nepomuceno, cuja decisão foi proferida em 09/06/2010, atraindo a inelegibilidade pelo prazo de 8 anos, a contar da decisão; terceiro, que o impugnado foi condenado pela prática de ato doloso de improbidade administrativa por órgão colegiado do Tribunal de Justiça de Minas Gerais, devido ao fornecimento gratuito de transporte para excursões para praia e romarias. A ação proposta foi julgada procedente, sem recorrer, o candidato renunciou a disputa eleitoral de 2016, lançando como substituta sua esposa, Sra. Cleuza Maria de Carvalho, conhecida como Cleuza do Silvio Lucas.

O candidato Luiz Fernando Pereira Souza (PROS) foi discretamente apoiado pelo prefeito atual, filiado ao Partido dos Trabalhadores (PT), devido aos desgastes políticos sofridos pelo PT no ano de 2016, em decorrência de denúncias de corrupção. Outro fato político que chamou a atenção dos cidadãos foi o apoio do atual vice-prefeito (DEM) à candidata oposicionista, Sra. Luiza Maria Lima Menezes (PSD), lançando-se novamente como vice-prefeito, agora como oposição.

Influenciar a opinião dos eleitores é o que importa durante a campanha eleitoral. O atual Prefeito, em discurso no ato cívico em comemoração ao aniversário de emancipação política-administrativa do município de Nepomuceno, no dia 30 de agosto de 2016, ressaltou as realizações de sua gestão, principalmente quanto às obras entregues e a renovação da frota de veículos, que foi apresentada em forma de desfile para a população que se encontrava em frente ao Paço Municipal. Estavam presentes o viceprefeito, candidato a vice novamente pela oposição, secretários municipais, autoridades, bem como os vereadores candidatos à reeleição, de todas as coligações.

O discurso proferido pelo Prefeito foi considerado abusivo pelo Ministério Público de Minas Gerais, por entender que o objetivo foi beneficiar os candidatos presentes e aqueles apoiados pelo atual governo, fato que acarretaria desequilíbrio da disputa eleitoral. Por esta razão, foi proposta uma representação eleitoral contra o atual Prefeito, contra todos os candidatos ao cargo de Prefeito, e contra aqueles vereadores candidatos à reeleição, que se encontravam próximo ao Chefe do Poder Executivo. Em juízo de primeira instância, somente o Prefeito foi condenado, com uma pena de multa.

A simples presença dos representados na frente do paço municipal não consiste em benefício bastante para aplicação de sanção, ainda que tenham seus nomes citados logo após o desfile dos carros da Prefeitura.

Nesse aspecto, qualquer sanção que se aplique aos candidatos se mostraria desproporcional com a conduta por eles realizada, apesar do comportamento do réu Marcos ter potencial de afetação da igualdade de oportunidade entre eles e os demais candidatos no presente pleito eleitoral.

Assim, concluo que apenas o representado Marcos Memento concorreu para a prática do ato violador da proibição da lei eleitoral.

Quanto ao grau de violação, para fins de análise da pena de multa a ser aplicada, é importante registrar: 1) tratava-se do aniversário da cidade; 2) houve desfile de carros da administração, com discurso no sentido de que eram os carros adquiridos naquele governo; 3) houve distribuição de bolo de aniversário da cidade, fato que não é comum, conforme depoimentos colhidos, pois apenas no aniversário do centenário da cidade, há cinco anos atrás, isso aconteceu, ou seja, permite concluir que não se trata de um costume local; 4) trata-se de prefeito em segundo mandato, ou seja, já participou de outros pleitos anteriores e sabe como funcionam as regras permissivas e proibitivas; 5) trata-se de prefeito que apoia candidato atual, inclusive tendo estacionado seu veículo com o adesivo do candidato que apoia entre os veículos da administração (indício que levou o Ministério Público a representar também outros candidatos do pleito e que teriam sido, ao ver do Parquet, beneficiados indiretamente); 6) O poder econômico e político do representado, na condição de prefeito municipal;

Levando em consideração os critérios acima mencionados, a pena não pode ser estabelecida no seu mínimo legal, razão pela qual, cotejando as circunstâncias do caso concreto, entendo que o patamar de 
$\mathrm{R} \$ 20.000,00$ (vinte mil reais) é suficiente, adequado e proporcional ao ato ilícito praticado (TRE-MG, 2016).

No que se refere à mídia como estratégia de campanha, a propaganda eleitoral foi veiculada através das rádios locais, tendo em vista que é o meio que atinge o maior número de eleitores no município. Os candidatos utilizaram-na, principalmente, como forma de ataque ao adversário, apontando as falhas de cada um. Além disso, a candidata Cleuza do Sílvio Lucas (PTB) se beneficiava do fato de contar com o nome e apoio de seu esposo na campanha eleitoral, por se tratar de um político populista e paternalista, de acordo com as sentenças condenatórias dos Tribunais, por utilizar de recurso público para angariar votos. O candidato Luiz Fernando (PROS), mesmo com o apoio discreto do atual governo, tinha a máquina pública a seu favor. A candidata Luiza Maria Lima Menezes (PSD), servidora pública municipal cedida para Assembleia Legislativa do Estado de Minas Gerais, atuou como assessora parlamentar do Deputado Estadual Fábio Cherem na região, permanecendo em Nepomuceno, além de exercer o trabalho voluntário de Presidente da Santa Casa de Misericórdia de Nepomuceno, que garantiu sua visibilidade no cenário políticosocial do município.

Outra ação importante para maximização dos votos é a coligação dos partidos. De acordo com a Lei Federal n ${ }^{\circ} 13.165$, de 29 de setembro de 2015, os partidos políticos devem escolher os seus candidatos e decidir as coligações que serão feitas até o dia 5 de agosto do ano das eleições. A coligação partidária é a união de dois ou mais partidos políticos para, em conjunto, apresentarem os seus candidatos para uma determinada eleição.

\footnotetext{
Perante a Justiça Eleitoral, uma coligação funciona como apenas um partido, tendo os mesmos direitos e deveres dos partidos políticos isolados. Depois de ser estabelecida uma coligação, nenhum dos partidos integrantes pode atuar isoladamente. O representante da coligação deverá ser escolhido pelos partidos que integram a coligação, e exercerá a mesma função do presidente do partido que concorre isolado (Eleições, 2016).
}

No município de Nepomuceno houve uma debandada de partidos políticos da base aliada do atual prefeito (PT), podemos destacar o Democratas (DEM), representado no governo atual pelo vice-prefeito e pelo Secretário Municipal de Administração, sendo esse último presidente do Diretório Municipal. A saída do DEM foi caso de ação judicial. Segundo as decisões judiciais da Justiça Eleitoral (TRE-MG, 2016), o Diretório Municipal do partido Democratas de Nepomuceno foi constituído em 16/08/2015 para ter exercício até 15/08/2018, mas que no dia 12/07/2016, às vésperas da convenção municipal designada para o dia 05/08/2016, o delegado da Executiva Estadual do DEM destituiu o Diretório Municipal, constituindo uma Comissão Provisória. Preliminarmente, o Diretório Municipal conseguiu uma liminar suspendendo a decisão da Executiva Estadual do DEM, no entanto, a liminar em poucos dias foi cassada. O processo segue até o momento sem julgamento final.

Toda esta celeuma é pano de fundo de uma disputa política, envolvendo os atuais prefeito e viceprefeito e a candidata a prefeita do PSD. O DEM local presidido pelo Secretário Municipal de Administração não tinha interesse em coligar com o PSD, por estar na base de apoio do atual prefeito. No entanto, o atual vice-prefeito manifestou interesse em se lançar candidato a vice-prefeito ao lado da candidata oposicionista do PSD. A destituição do Diretório Municipal do DEM de Nepomuceno foi uma clara luta de poder e influência política entre os pré-candidatos, diante da Executiva Estadual e Nacional do DEM.

Essas coalizões objetivam concentrar poder político para as eleições municipais e não são realizadas apenas por similaridades entre as ideologias partidárias, mas, principalmente, por acordos visando benefícios aos partidos que irão fornecer seu apoio. Esses benefícios vão desde promessas de cargos para a composição do novo governo a financiamento de políticas públicas à entes mais regionalizados. $\mathrm{O}$ apoio local é importante para a formação de redes locais de distribuição de recursos e coleta de informações sobre os eleitores (Borges, 2013).

[...] Os partidos clientelistas são, por definição, organizações descentralizadas que se apoiam em um exército de intermediários políticos e cabos eleitorais para coletar informações sobre o eleitorado, distribuir recursos e monitorar os eleitores para que estes cumpram a sua parte na barganha apoiando os candidatos governistas (Borges, 2013, p. 125). 
Dessa forma, o DEM abandonou a base do atual governo, coligando-se com a oposição, lançando novamente o Sr. José Maria de Oliveira como vice-prefeito da chapa "Um novo tempo para todos" (PP / PSD / SD / DEM / PSDB / PR / PDT).

As eleições chegaram ao fim sem que os eleitores tivessem conhecimento sobre os planos de governo dos três principais candidatos, até mesmo pela redução do período de campanha eleitoral para 45 (quarenta e cinco) dias, estabelecido pela Lei $\mathrm{n}^{0}$ 13.165/2015, que alterou a legislação eleitoral. Os partidos, muitas vezes, evitam divulgar seus programas para prevenir danos que poderiam advir dessa exposição, ademais, os brasileiros não se interessam muito pelos planos de governo dos candidatos Eles se interessam mais pela personalidade dos candidatos e seus "ideais". (Villa, 2014).

O resultado final das eleições municipais de 2016 concedeu a vitória a Luiza Maria Lima Menezes (PSD) e seu vice, José Maria de Oliveira (DEM), que receberam 5.214 votos, o que representou 36,96 dos votos válidos. Luiz Fernando Pereira Souza (PROS) e seu vice, Thuler Adriano Spuri (PSB), obtiveram 4.531 votos (32,12\% dos votos válidos). Cleuza do Silvio Lucas (PTB) e seu vice Vicente Tomaz Azarias (PSL), obtiveram 4.363 votos (30,93\% dos votos válidos). Dos 20.561eleitores aptos a votar, compareceram 16.605 eleitores (80,76\%). Desse total, foram 829 votos em branco e 1.668 votos nulos (TRE-MG, 2016).

As eleições municipais de 2016 foram marcadas pela a aplicação da Lei ${ }^{\circ} 13.165 / 2015$, que teve como finalidade a redução dos custos das campanhas eleitorais, simplificar a administração dos partidos políticos e incentivar a participação feminina. Destacamos aqui as principais alterações no processo de financiamento e prestação de contas das campanhas: novas regras para fixação dos limites de gastos, administração financeira, abertura de conta bancária e doações; apuração da doação acima do limite legal; legitimidade para apresentação das contas e sistema simplificado; novo prazo para apresentação das contas e para seu julgamento; divulgação imediata das doações recebidas, prestação de contas parcial, comprovação de gastos com passagens aéreas, transferência pelos partidos a candidatos de recursos oriundos de doação e vínculo empregatício na contratação de pessoal. Além de tudo, o período de campanha eleitoral foi reduzido pela metade, objetivando a redução dos gastos com propaganda eleitoral (Waldschmidt, 2015).

\section{Conclusão}

Objetivou-se com este artigo teórico apresentar os conceitos centrais acerca da democracia de Rousseau e demonstrar como a dominação patrimonialista tem usurpado o caráter democrático das eleições municipais, por meio de uma análise da campanha eleitoral de 2016 no município de Nepomuceno/MG. Para isso, discutiu-se o processo de formação de Estado, soberania e democracia dentro da visão dos filósofos contratualistas para se compreender melhor o posicionamento de Rousseau sobre o assunto. Posteriormente, o conceito de democracia foi tratado sob uma ótica mais recente para se demonstrar a relação entre o pensamento daquele filósofo e o que existe na atualidade. Apresentou-se o conceito de dominação patrimonialista de Weber e como o processo eleitoral brasileiro foi construído sob a sua influência.

E para demonstrar a presença das características patrimonialistas em ameaça constante à democracia, foram relacionados alguns acontecimentos presentes nas eleições de 2016 no município de Nepomuceno-MG. Como um reflexo ou uma continuação da história das eleições brasileiras, que foram marcadas por fraudes, manipulações, coronelismo, a cultura que permeia esse processo ainda se baseia no controle da vontade do eleitorado pelos políticos, que utilizam de instrumentos herdados do patrimonialismo: quando os candidatos buscam apoio de outros, como no caso do apoio do atual prefeito ao Luiz Fernando ou do vice-prefeito à Luiza Maria, percebe-se o caráter personalístico da política brasileira, a influência do prestígio, da confusão da pessoa com o cargo que ela ocupa; a manutenção da "santidade da tradição" quando afirmam que vão dar continuidade aos feitos de seus antecessores, na manutenção de políticas públicas existentes; o discurso do prefeito, em exercício na época da campanha, que ressaltou as realizações de seu governo demonstram a utilização de políticas sociais como moeda de troca na compra de votos daqueles que realmente necessitam das políticas assistenciais do governo, como se elas fossem um favor pessoal e não uma 
obrigação do governante na busca por maior justiça social; além disso, esse fato caracteriza a utilização da máquina pública como instrumento de campanha, sem distinção entre o público e o particular; a prática de coalizões políticas com o objetivo de garantir que o candidato se comprometa com outros partidos para que, se eleito, conceda aos seus integrantes "cargos patrimoniais", ratificando a presença do clientelismo; o desconhecimento do plano de governo dos candidatos pelos eleitores demonstra o foco na pessoa do candidato e não na técnica a ser implementada. Por fim, todo o relato torna clara a exista velha conhecida corrupção, que faz da campanha política um meio de desviar recursos públicos, comprar pessoas, obter benefícios próprios e manipular as massas por meio de campanhas ostensivas.

Tudo isso, acentuado pelas ferramentas de dominação da sociedade moderna: o marketing, a propaganda, a mídia. Por meio desses instrumentos que, praticamente, se confundem em um só, é possível conhecer as necessidades, os desejos, as fraquezas dos cidadãos e utilizar essas informações para influenciar e dominá-los.

Dessa forma, mesmo que hoje os brasileiros apresentem maior interesse pelos assuntos políticos, participando um pouco mais das decisões por meio das organizações sociais, o resgate da história eleitoral brasileira associado a este estudo de caso conduz à reflexão sobre o fato de que a herança patrimonialista compromete o caráter democrático das eleições municipais no país, corroborando para a perpetuação das relações dependência entre dominantes e dominados, o que reafirma o estágio incipiente da democracia no Brasil, principalmente quando voltamos ao conceito de Rousseau que via nas eleições o ápice de seu exercício. Conclui-se que o acordo tácito de poder, baseado no fator econômico, se mantém entremeado na democracia brasileira e apenas por meio do voto não é possível romper com essa estrutura patrimonialista e personalista. 


\section{BIBLIOGRAFÍA}

Abrucio, F. L. (2007). Trajetória recente da gestão pública brasileira: um balanço crítico e a renovação da agenda de reformas. Revista de Administração Pública-RAP, 41.

Ames, J. L. (2006). Religião e política no pensamento de Maquiavel. Kriterion: Revista de Filosofia, 47(113), 51-72.

Andrade, D. M., de Carvalho Castro, C. L., \& Pereira, J. R. (2012). Cidadania ou "estadania" na gestão pública brasileira?. Revista de Administração Pública, 46(1), 177-190.

Borges, A. (2013). Eleições presidenciais, federalismo e política social. Revista Brasileira de Ciências Sociais, 28(81).

Bresser-Pereira, L. C. (2009). Construindo o Estado republicano: democracia e reforma da gestão pública. Fgv.

Cançado, A. C., Pereira, J. R., \& Tenório, F. G. (2013). Gestão social: epistemologia de um paradigma. Curitiba: CRV.

Carvalho, J. M. D. (1997). Mandonismo, coronelismo, clientelismo: uma discussão conceitual. Dados, 40(2).

Carvalho, J. M. D. (2000). Rui Barbosa e a razão clientelista.

Costa, F. L. D. (2008). Brasil: 200 anos de Estado; 200 anos de administração pública; 200 anos de reformas.

de Oliveira, R. F., da Silva e Oliveira, V. C. \& dos Santos, A. C. (2011). Beneficiários ou reféns? O patrimonialismo na perspectiva dos cidadãos de Poço Fundo, Minas Gerais. Cadernos EBAPE. BR, 9(4).

Eleições (2016). Como funciona uma coligação partidária. Recuperado em 15 dezembro, 2016 de https://www.eleicoes2016.com.br/como-funciona-uma-coligacao-partidaria/.

ELEITORAL, T. S. Tribunal Superior Eleitoral. Folha On Line. Disponível em: www.tse.gov.br/tre Acesso em 12 de ago 2016

Faoro, R. (2001). Os donos do poder. Formação do patronato político brasileiro, 3.

Gil, A. C. (2008). Métodos e técnicas de pesquisa social. 6. ed. Ediitora Atlas SA.

Hobbes, T. (2005). Leviatã. Tradução de Alex Martins. São Paulo: Martin Claret, 2005.

Kauark, F. D. S., Manhães, F. C., \& Medeiros, C. H. (2010). Metodologia da pesquisa: um guia prático.

Leal, V. N. (2012). Coronelismo, enxada e voto: o município e o regime representativo no Brasil. Editora Companhia das Letras.

Locke, J. (1998). Dois tratados sobre o governo. São Paulo: Martins Fontes.

Moisés, J. Á. (2010). Os significados da democracia segundo os brasileiros. Opinião Pública, 16(2), 269-309.

Nicolau, J. (2012). Eleições no Brasil: do Império aos dias atuais. Zahar.

Rennó, L., \& Ames, B. (2014). PT no purgatório: ambivalência eleitoral no primeiro turno das eleições presidenciais de 2010. Opinião Pública, 20(1), 01-25.

ROUSSEAU, Jean Jacques. O contrato social. São Paulo: Cultrix, 1989.

Rubim, A. A. C., \& Colling, L. (2005). Mídia, cultura e eleições presidenciais no Brasil contemporâneo. Comunicação e política. Covilhã: Universidade da Beira Interior, 1, 11-44.

Tribunal Regional Eleitoral - TRE-MG (2016). Agravo de Instrumento. Ação Anulatória de Dissolução de Comissão Executiva Municipal. Recurso Eleitoral no 313-33.2016.6.13.0000. Agravante: Wagner Lúcio Spuri, Presidente do Diretório Municipal do Democratas - DEM. Agravados: Democratas - DEM, Diretório Estadual; Democratas - DEM, Diretório Nacional; Democratas - DEM, Comissão Provisória Municipal. Juiz: Paulo Abrantes. Belo Horizonte. Recuperado em 16 dezembro, 2016 de http:/www.jusbrasil.com.br/topicos/92423728/democratas-dem-comissaoprovisoria-municipal.

Tribunal Regional Eleitoral - TRE-MG (2016). Liminar. Ação Anulatória de Dissolução de Comissão Executiva Municipal. Processo n ${ }^{\circ}$ 0000039-75.2016.6.13.0192. Autor: Wagner Lúcio Spuri. Réu: Diretório Nacional do Democratas - DEM, Comissão Provisória do Democratas - DEM Nepomuceno. Juiz Felipe Manzanares Tonon. Nepomuceno. Recuperado em 16 dezembro, 2016 de http://www.tre-mg.jus.br/@@processrequest. 
Tribunal Regional Eleitoral - TRE-MG (2016). Sentença. Impugnação ao Registro de Candidatura. Processo no 0000085 64.2016.6.13.0192. Requerente: Coligação de Volta para o Progresso (PTB/PSL/PHS). Impugnante: Ministério Público Eleitoral, Coligação "Um novo tempo para todos". Candidato: José Sílvio de Carvalho. Juiz Felipe Manzanares Tonon. Nepomuceno, Recuperado em 16 dezembro, 2016 de http://www.tre-mg.jus.br/@@processrequest.

Waldschmidt, H. (2015). Breves notas sobre a minirreforma eleitoral de 2015. Campo Grande:[sn], 1-30.

Weber, M. (1999). Economia e sociedade: fundamentos da sociologia compreensiva. v. 1. Brasília: UnB, 209-227. 